\title{
Effects of arachidonate-enriched triacylglycerol supplementation on serum fatty acids and platelet aggregation in healthy male subjects with a fish diet
}

\author{
Aki Kusumoto $^{1 *}$, Yoshiyuki Ishikura ${ }^{1}$, Hiroshi Kawashima ${ }^{1}$, Yoshinobu Kiso ${ }^{1}$, Shinji Takai ${ }^{2}$ \\ and Mizuo Miyazaki ${ }^{2}$ \\ ${ }^{1}$ Institute for Health Care Science, Suntory Ltd., 1-1-1 Wakayamadai, Shimamoto-cho, Mishima-gun, Osaka 618-8503, Japan \\ ${ }^{2}$ Department of Pharmacology, Osaka Medical College, 2-7 Daigaku-machi, Takatsuki, Osaka, Japan
}

(Received 4 October 2006 - Revised 28 February 2007 - Accepted 1 March 2007)

\begin{abstract}
The changes in fatty acid composition of serum and in platelet aggregation induced by supplementation of arachidonate-enriched TAG were investigated in twenty-four healthy Japanese men in a double-blind, placebo-controlled study. The arachidonate-enriched TAG ingested was an edible oil, extracted and purified from a biomass of submerged fermented Mortierella alpina. Mean daily intake of fish and shellfish by subjects was 87.2 (SE5.3) g/d, while dietary intakes of arachidonic acid (ARA) by the ARA group and placebo group were 175 (SE12) and 179 (SE13) mg/d, respectively. In the ARA group, after 2-week supplementation of $838 \mathrm{mg} \mathrm{ARA} / \mathrm{d}$, ARA concentration in serum phospholipids was increased from 9.6 (SE0.4) to 13.7 (SE0.4) g/100 g total fatty acids, and was significantly different from that in the placebo group $(P<0.001)$. This level was maintained for 4 weeks but returned to baseline level after a 4-week washout period. Linoleic acid concentration in serum phospholipids decreased from $19 \cdot 2$ (SE0.8) to 16.3 (SE0.6) g/100 g total fatty acids in the ARA group. Similarly, ARA content of serum TAG increased after ARA supplementation. Neither the EPA nor DHA content of serum phospholipids or TAG was altered by ARA supplementation. The platelet aggregation induced in platelet-rich plasma by adding adenosine diphosphate, collagen and ARA, physical characteristics of subjects, and biochemical parameters were unchanged throughout the test period. These findings suggest that ARA concentration in serum phospholipids and TAG can be safely increased by supplementation of arachidonate-enriched TAG oil.
\end{abstract}

Arachidonic acid: Serum: Platelet aggregation: Man

Arachidonic acid (ARA; $20: 4 n-6$ ) is a PUFA and major constituent of the cell membrane, and plays important roles in the preservation of physiological function. For example, yolk, lean meat and fish contain comparatively large amounts of ARA. In the last several decades, many studies have focused on the usefulness of $n-6$ PUFA $^{1-3}$ and $n-3$ PUFA $^{2-6}$ in atherosclerosis, and of the latter in dementia ${ }^{7-10}$. There are many official recommendations of the ratio of $n-6$ to $n-3$ fatty acids. For example, the WHO/FAO suggests a ratio of $5: 1-$ $10: 1^{11}$, the National Institutes of Health recommends a ratio of $2: 1-3: 1^{12}$ and Canada recommends $4: 1-10: 1^{13}$. Also, there are recommended dietary intakes for specific fatty acids, such as linoleic acid (18:2n-6), $\alpha$-linolenic acid $(18: 3 n-3)$ and EPA $(20: 5 n-3)+$ DHA $(20: 6 n-3)$, proposed by the $\mathrm{UK}^{14}$, National Institutes of Health ${ }^{3}$ and American Heart Association. Whereas there are no official recommendations for ARA.

In the human body, ARA is synthesized through desaturation and elongation of linoleic acid. That process is similar to the synthesis of EPA and not as complex as that of DHA, from $\alpha$-linolenic acid. However, human fetuses and neonates are unable to synthesize ARA and DHA sufficiently, and initially obtain ARA and DHA by placental transfer and from human milk ${ }^{15-18}$. It has been reported that premature babies given infant formulas containing ARA and DHA grew better than babies given formulas not containing them ${ }^{19,20}$. Even for term infants, use of infant formulas containing ARA and DHA yielded better developmental outcomes than unsupplemented formulas ${ }^{21-23}$. ARA and DHA are commonly found in infant formulas in Europe and the USA, because the usefulness of addition of them to the diet has been examined by many advisory bodies (e.g. ESPGAN ${ }^{24}$, the British Nutrition Foundation Task Force ${ }^{25}$ and $\mathrm{SCF}^{26}$ ). It has been found that the capacity to convert $\alpha$-linolenic acid to EPA and DHA is low beyond infancy ${ }^{27-29}$, and that the principal converting enzyme, $\Delta 6$-desaturase, becomes less efficient with ageing ${ }^{30}$. In healthy women, it has been reported that the conversion of $\left[{ }^{13} \mathrm{C}\right]$ linoleic acid and $\left[{ }^{13} \mathrm{C}\right] \alpha$-linolenic acid to longer-chain PUFA is a quantitatively minor route of utilization $^{31}$.

The content of ARA in membrane phospholipids has been found to be lower in aged than in young animals. Several studies have found that the ability of aged rats to sustain long-term potentiation, which is thought to be a strong model for neuronal plasticity such as learning and memory in the hippocampus ${ }^{32}$, is impaired. Also it has been revealed 
that the impairment of sustaining long-term potentiation is coupled with a decrease in membrane ARA concentration in the dentate gyrus ${ }^{33,34}$. In addition, results of spatial task performance and ARA studies as well as studies of ARA and long-term potentiation have suggested the possibility that spatial learning deficits in aged rats may be improved by administration of $\mathrm{ARA}^{33-38}$.

It has been expected that highly purified oils rich in ARA will come into use not only in infant formulas but also nutritional products and food supplements. In the last few decades, advances in microbiological technology have enabled supplementation of ARA in TAG oil ${ }^{39}$.

Safety studies of ARA-enriched TAG oil obtained from Mortierella alpina have been performed both in vitro and in vivo ${ }^{40-43}$. There have been several human studies of ARA-enriched TAG, including one in healthy subjects using $1.5 \mathrm{~g} / \mathrm{d}$ for $50 \mathrm{~d}^{44-48}$ and one in patients with cirrhosis using $2 \mathrm{~g} / \mathrm{d}$ for 8 weeks $^{47}$. Both studies found that supplementation of ARA-enriched TAG safely increased ARA concentration in plasma and erythrocytes. Because the body composition of fatty acids is affected by diet, studies are needed in other types of individuals, e.g. those with moderate fish intake and who thus have comparatively high levels of EPA and DHA in the blood and cell membranes, such as the Japanese ${ }^{48-52}$.

In the present study, we examined the effects of ARAenriched TAG supplementation on the composition of serum fatty acids, platelet aggregation and biomedical parameters in healthy Japanese men, who have comparatively high levels of EPA and DHA in blood.

\section{Experimental methods}

\section{Subjects}

Healthy male subjects were recruited after assessment of medical and dietary histories. Exclusion criteria were the presence of overt vascular, haematological or respiratory disease, hyperlipidaemia, infection, BMI less than 19 or greater than $27 \mathrm{~kg} / \mathrm{m}^{2}$, smoking and consumption of drugs that affect lipid metabolism or haemostatic function. All subjects were asked not to change anything related to nutrition or lifestyle during the test period, in order to eliminate effects of such changes on certain haemostatic factors. The subjects were supplied with sufficient explanation concerning the study, they understood it well and they provided written informed consent.

\section{Study design}

This double-blind, placebo-controlled study included three periods, run-in (1 week), supplementation (4 weeks) and post-supplementation (4 weeks, washout), which together formed the test period. The study was approved by the Ethics Committee on Human Experimentation of Suntory and conformed to the Helsinki Declaration. Subjects were randomly divided into two groups. One group received capsules containing $200 \mathrm{mg} / \mathrm{capsule}$ TAG enriched with ARA (corresponding to $83.8 \mathrm{mg} /$ capsule), which was extracted from a biomass of submerged fermented $M$. alpina and refined by high-purification processes (SUNTGA40S; Suntory Ltd, Osaka, Japan). Another group received capsules containing
$200 \mathrm{mg} / \mathrm{capsule}$ commercially available olive oil as a placebo. The fatty acid compositions of the two oils are shown in Table 1. Subjects were instructed to take ten capsules every morning during the supplementation period. ARA content in the capsules was $83.8 \mathrm{mg} / \mathrm{capsule}$ and therefore the daily ARA dose was $838 \mathrm{mg} / \mathrm{d}$ in the ARA group.

\section{Dietary design}

The subjects were asked to continue their habitual diet and keep a diary regarding their health condition and daily intake of eggs, fish and meat, in order to roughly monitor consumption of ARA and other nutrients. Daily food intake by each subject was estimated by $7 \mathrm{~d}$ weighed intake. Nutrient intakes were calculated by the software Eiyoukun (version 4.0) for Microsoft Excel (Kenpakusha, Japan), which was based on the Standard Tables of Food Composition in Japan $^{53}$. Because certain dietary components, such as garlic, onion, fermented soyabeans, some spices and alcohol, are known to modify platelet aggregation, the subjects were given written and verbal instructions not to exceed the usual intake of each during the test period. Each subject was instructed to have the same dinner each evening before blood sampling, and they did not allowed alcohol and fermented soyabeans the day before blood sampling.

\section{Procedure for measurements and blood sampling}

The physical characteristics of subjects were measured and blood and urine were collected for fatty acid analysis, determination of biochemical parameters and platelet aggregation, and urinalysis. Samples were obtained after a $13 \mathrm{~h}$ fast in the early morning before consumption of the capsules at 0,2 and 4

Table 1. Fatty acid composition of the study oils (as \% of total fatty acids)

\begin{tabular}{lrr}
\hline Fatty acid & Placebo & ARA \\
\hline $8: 0$ & $0 \cdot 7$ & $0 \cdot 4$ \\
$10: 0$ & $0 \cdot 2$ & $0 \cdot 2$ \\
$14: 0$ & $0 \cdot 0$ & $0 \cdot 5$ \\
$15: 0$ & $0 \cdot 0$ & $0 \cdot 2$ \\
$16: 0$ & $11 \cdot 9$ & $10 \cdot 0$ \\
$16: 1 n-7$ & $1 \cdot 2$ & $0 \cdot 0$ \\
$17: 0$ & $0 \cdot 0$ & $0 \cdot 4$ \\
$18: 0$ & $2 \cdot 8$ & $7 \cdot 3$ \\
$18: 1 n-9$ & $70 \cdot 8$ & $6 \cdot 9$ \\
$18: 2 n-6$ & $11 \cdot 1$ & $9 \cdot 7$ \\
$18: 3 n-6$ & $0 \cdot 0$ & $2 \cdot 4$ \\
$18: 3 n-3$ & $0 \cdot 6$ & 0.5 \\
$20: 0$ & $0 \cdot 4$ & 0.9 \\
$20: 1 n-9$ & $0 \cdot 3$ & $0 \cdot 4$ \\
$20: 2 n-6$ & $0 \cdot 0$ & $0 \cdot 6$ \\
$20: 3 n-6$ & $0 \cdot 0$ & 3.5 \\
$20: 4 n-6$ (ARA) & $0 \cdot 0$ & $41 \cdot 9$ \\
$20: 5 n-3$ (EPA) & $0 \cdot 0$ & $0 \cdot 1$ \\
$22: 0$ & $0 \cdot 0$ & $3 \cdot 5$ \\
$22: 4 n-6$ & $0 \cdot 0$ & $0 \cdot 6$ \\
$24: 0$ & $0 \cdot 0$ & $9 \cdot 2$ \\
$24: 1 n-9$ & $0 \cdot 0$ & $0 \cdot 3$ \\
Unknown & $0 \cdot 0$ & $0 \cdot 5$ \\
\hline ARA a & & \\
\hline & &
\end{tabular}

ARA, arachidonic acid. 
weeks and after the 4-week washout period. Times of measurement and sampling were standardized across the test period to minimize effects of circadian variation. Samples were obtained and measurements performed after subjects had been sitting quietly for $15 \mathrm{~min}$. Body weight and blood pressure were measured as physical characteristics. Blood pressure measurements were made using the HEM-1000 automatic digital manometer (Omron Healthcare Co., Kyoto, Japan). Recordings were made in duplicate, and consistent values or averages were taken. Venous blood samples were taken from the arm not used for measurement of blood pressure using a 21-gauge needle and syringe.

\section{Fatty acid analysis}

Serum was prepared from $3 \mathrm{ml}$ blood using the method described earlier. Lipids in the serum were extracted and purified $^{54}$ and separated into neutral lipids and phospholipids by TLC with silica gel 60 (Merck, Darmstadt, Germany). The solvent system consisted of hexane-diethyl ether $(7: 3, \mathrm{v} / \mathrm{v})$. Fatty acid residues in the phospholipid and TAG fractions were analysed ${ }^{39}$. In brief, each fraction with an additional internal standard (pentadecanoic acid) was incubated in methanolic $\mathrm{HCl}$ at $50^{\circ} \mathrm{C}$ for $3 \mathrm{~h}$ for transmethylation of fatty acid residues to fatty acid methyl esters. Fatty acid methyl esters were extracted with $n$-hexane and analysed by capillary GLC using pentadecanoic acid as an internal standard.

\section{Analyses of haematological and biochemical parameters}

Standard haematological tests were determined using a Sysmex SE-9000 (Sysmex Co., Kobe, Japan). Standard clinical chemistry tests, phospholipids (choline oxidase method $^{55}$ ), HDL-cholesterol ${ }^{56}$, LDL-cholesterol ${ }^{57}$ and C-reactive protein (latex agglutination immunoassay ${ }^{58,59}$ ) were performed on a Model 7450 (7170) or 7070 Hitachi Automatic Clinical Analyzer (Hitachi High Technologies Co., Tokyo, Japan). Serum IgE was measured by fluorescence enzyme immunoassay, using a Uni CAP 1000 (Aloka Co., Tokyo, Japan). Plasma for blood glucose determination was prepared from blood $(2 \mathrm{ml})$ collected into a tube containing heparin as an anticoagulant and $\mathrm{Na}$-fluorine as a stop reagent, by immediate centrifugation at $2150 \mathrm{~g}$ for $10 \mathrm{~min}$ at $4^{\circ} \mathrm{C}$, and was analysed by the hexokinase-glucose-6-phoshate dehydrogenase method in a JCA-BM12 (Jeol, Tokyo, Japan). Plasma for prothrombin time and antithrombin III determination was prepared from $1.8 \mathrm{ml}$ blood collected into a tube containing $0.2 \mathrm{ml}$ sodium citrate as an anticoagulant (final concentration $13 \mathrm{~mm}$ ), and centrifuged at $2150 \mathrm{~g}$ for $10 \mathrm{~min}$ at $4^{\circ} \mathrm{C}$. Prothrombin time was determined by the Quick one-step test and antithrombin III activity by the chromogenic method, using the Sysmex CA7000. Urinalysis was performed using the AUTION MAX AX-4280 (Eiken Chemical Co., Tokyo, Japan) to determine density and $\mathrm{pH}$ and for detection of glucose, protein, blood, urobilinogen, bilirubin and ketone bodies.

\section{Platelet aggregation study}

Venous blood $(13.5 \mathrm{ml})$ was collected through siliconized needles into three plastic tubes, with $4.5 \mathrm{ml}$ in each tube containing $0.5 \mathrm{ml} 3.8 \%$ sodium citrate (final concentration $13 \mathrm{~mm}$ ). Platelet-rich plasma was obtained by centrifugation of blood at $190 \mathrm{~g}$ for $15 \mathrm{~min}$ at $22^{\circ} \mathrm{C}$. Platelet-poor plasma was prepared by respinning the blood after removal of the platelet-rich plasma at $1700 \mathrm{~g}$ for $10 \mathrm{~min}$. Platelet aggregation was measured in duplicate in a twelve-channel MCM Hematracer (MC Medical Inc., Tokyo, Japan). A $200 \mu$ l portion of the platelet-rich plasma was added to a silicon-coated tube containing a stirring bar at a speed of $1000 \mathrm{rpm}$ at $37^{\circ} \mathrm{C}$. The blank was $200 \mu$ l of the individual's platelet-poor plasma, unstirred. Aggregation of platelets in platelet-rich plasma was induced by adding specified concentrations of ADP (Sigma-Aldrich Co., St Louis, MO, USA), collagen (Hormon-Chemie Munchen $\mathrm{GmbH}^{60,61}$ ) and ARA (Nacalai Tesque, Inc., Kyoto, Japan), and measured as the increase in transmission of light through platelet-rich plasma for $15 \mathrm{~min}$. Values are expressed as percentages of maximal aggregation induced by the aggregating agents, which were 1 and $2 \mu \mathrm{M}$ ADP, 0.125 and $0.25 \mu \mathrm{g}$ collagen/ml, and 0.5 and $1 \mu \mathrm{M}$-ARA, and as concentration of aggregating agent required to elicit half-maximal response $\left(\mathrm{ED}_{50}\right)$ for $\mathrm{ADP}$ and collagen. Platelet aggregation was performed within $3 \mathrm{~h}$ of blood withdrawal.

\section{Statistical analysis}

All values are expressed as means with their standard errors of the means for the subjects in each experimental group. Findings were examined by two-way ANOVA without repeated measures, using time and group as sources of variation. Student's unpaired $t$ test was used to determine differences between two treatment groups. Determination of the significance of differences between measurements within the same group before and after the intervention was performed with Bonferroni correction for multiple comparisons. Significance of findings was accepted at $P<0 \cdot 05$. The Statistical Package for the Social Sciences for Windows version 11.5 (SPSS Inc., Chicago, IL, USA) was used for statistical analyses.

\section{Results}

A total of twenty-eight subjects entered the study, and ranged in age from 26 to 60 years. Baseline characteristics were similar in the two groups. There was no statistically significant difference between the two groups with respect to age, body weight or BMI. Four subjects were withdrawn (one in the placebo group had tonsillitis and took anti-inflammatory drugs; one in the ARA group had an infectious disease and fever at the time of the 4-week blood draw; the other two subjects were withdrawn because of ingestion of anti-inflammatory drugs (one in the placebo group, one in the ARA group)). All of the twenty-eight subjects were included in the safety analysis. None of the subjects reported any detrimental sideeffects. All adverse events observed during the test period were considered unrelated to supplementation. A total of twenty-four subjects (twelve in the placebo and twelve in the ARA group) completed the trial. The mean ages of these subjects in the placebo and ARA groups were 38.6 (SE 3.3) and $39 \cdot 8$ (SE 2.2) years, respectively. 


\section{Nutrient intakes}

Table 2 shows the proportions of macronutrients and intakes of energy and some fatty acids associated with the background diet of subjects (not including supplements for the placebo and ARA groups). None of daily food intakes differed between the two groups (Table 2). The fish and shellfish intake of allsubjects in the present study was 87.2 (SE 5.3) g/d, while their meat intake was 115.5 (SE 8.1) g/d.

\section{Serum fatty acid composition}

The fatty acid compositions of serum phospholipids and TAG are shown in Tables 3 and 4. They did not differ between the two groups at baseline. Following ARA supplementation, ARA content of serum phospholipids increased significantly at 2 weeks $(P<0 \cdot 001)$ and 4 weeks $(P<0.001)$, and returned to baseline level after the 4 -week washout period. However, no other serum phospholipid fatty acid was significantly changed in the ARA supplementation group compared with the placebo group. In the ARA group alone, stearic acid (18:0) content in serum phospholipids was significantly increased and linoleic acid $(18: 2 n-6)$ content decreased at 2 and 4 weeks compared to baseline. EPA content was 27.7 (SE 2.5) $\mu \mathrm{g} / \mathrm{ml}$ and DHA was 92.3 (SE 2.9) $\mu \mathrm{g} / \mathrm{ml}$ at 0 weeks, and neither EPA nor DHA content was changed after ARA supplementation.

The ARA content of serum TAG also increased significantly after ARA supplementation at 2 and 4 weeks $(P<0 \cdot 01)$, and returned after the washout period. As for serum phospholipids, EPA and DHA contents in serum TAG were not altered by ARA supplementation. In the ARA group, $16: 1$ and $18: 1 n-9$ contents of serum TAG negligibly but significantly changed after washout, compared with baseline.

\section{Physical characteristics, haematological and biochemical parameters}

The physical characteristics and main blood biochemical parameters of the subjects of the two groups are shown in Table 5. In neither group did mean values of the parameters change during the test period, and no significant differences were observed between the two groups at pretreatment or at any time-point during the test period. No differences was observed in results of haematological tests, which were blood $\mathrm{Hb}$, packed cell volume, counts of erythrocytes, total leucocytes, thrombocytes, mean of corpuscular volume and $\mathrm{Hb}$ concentration, and urinalysis between the two groups or during the test period.

\section{Platelet aggregation}

Table 6 shows platelet aggregation as percentages of maximal aggregation by ADP, collagen and ARA. No significant differences were observed in aggregation response between the two groups. In both groups, maximal aggregation by $0.25 \mu \mathrm{g}$ collage $/ \mathrm{ml}$ was significantly increased at 4 weeks compared with pretreatment ( 0 weeks), while in the placebo group alone it was still increased after the washout period. Table 7 shows the concentrations of aggregating agents, ADP and collagen, required to induce approximately half-maximal response $\left(\mathrm{ED}_{50}\right)$. No significant difference was observed in $\mathrm{ED}_{50}$ between the two groups, and in neither group was a significant difference observed between pretreatment ( 0 weeks) and other time-points.

Table 2. Subjects' daily food intake estimated by $7 \mathrm{~d}$ weighed intake for the arachidonic acid (ARA) treatment group $(n 12)$ and placebo group $(n 12) \ddagger$

(Mean values with their standard errors)

\begin{tabular}{|c|c|c|c|c|c|c|c|c|}
\hline \multirow[b]{2}{*}{ Nutrient } & \multicolumn{4}{|c|}{ Placebo } & \multicolumn{4}{|c|}{ ARA } \\
\hline & Mean & SE & Minimum & Maximal & Mean & SE & Minimum & Maximal \\
\hline Energy (MJ) & 8.64 & 0.27 & & & 9.32 & 0.37 & & \\
\hline Protein (E\%) & 13.9 & 0.4 & & & $13 \cdot 8$ & 0.4 & & \\
\hline Carbohydrate (E\%) & $49 \cdot 0$ & 1.7 & & & 49.7 & 1.8 & & \\
\hline Total fat (E\%) & $28 \cdot 0$ & $1 \cdot 1$ & & & $27 \cdot 6$ & 1.5 & & \\
\hline SFA (E\%) & 7.83 & 0.51 & & & $7 \cdot 61$ & 0.54 & & \\
\hline MUFA (E\%) & $10 \cdot 79$ & 0.46 & & & $10 \cdot 37$ & 0.66 & & \\
\hline PUFA (E\%) & 5.98 & 0.30 & & & $6 \cdot 13$ & 0.34 & & \\
\hline Protein $(\mathrm{g})$ & 71.5 & 2.5 & & & $76 \cdot 1$ & 1.9 & & \\
\hline Carbohydrate (g) & 252 & 10 & & & 277 & 16 & & \\
\hline Total fat $(\mathrm{g})$ & 64.8 & 4.2 & & & $67 \cdot 7$ & 3.8 & & \\
\hline SFA (g) & $18 \cdot 1$ & 1.5 & & & $18 \cdot 7$ & 1.4 & & \\
\hline MUFA (g) & $25 \cdot 0$ & 1.7 & & & 25.5 & 1.7 & & \\
\hline PUFA (g) & 13.8 & $1 \cdot 0$ & & & $15 \cdot 0$ & 0.8 & & \\
\hline$n-3$ Fatty acids (g) & 2.66 & 0.24 & & & $2 \cdot 74$ & 0.19 & & \\
\hline$n-6$ Fatty acids (g) & $11 \cdot 2$ & 0.8 & & & $12 \cdot 2$ & 0.8 & & \\
\hline $18: 3 n-3(\mathrm{~g})$ & 1.51 & 0.14 & 0.753 & $2 \cdot 36$ & 1.66 & 0.11 & 1.07 & $2 \cdot 29$ \\
\hline $18: 3 n-6(\mathrm{~g})$ & $10 \cdot 8$ & 0.8 & 6.76 & $16 \cdot 1$ & 11.9 & 0.7 & 8.58 & $16 \cdot 7$ \\
\hline $20: 4 n-6$ (ARA) (mg) & 175 & 12 & 110 & 230 & 179 & 13 & 110 & 271 \\
\hline $20: 5 n-3$ (EPA) (mg) & 318 & 46 & 42 & 634 & 311 & 56 & 59 & 691 \\
\hline $22: 6 n-3(\mathrm{DHA})(\mathrm{mg})$ & 564 & 71 & 98 & 991 & 530 & 72 & 180 & 935 \\
\hline
\end{tabular}

$\mathrm{E} \%$, percentage energy intake.

$\ddagger$ No significant difference was observed between the two groups for any of the parameters. 
Table 3. Fatty acid composition ( $\mathrm{g} / 100 \mathrm{~g}$ total fatty acids) of serum phospholipids during the test period for the arachidonic acid (ARA) treatment group $(n$ 12) and placebo group ( $n$ 12) (Mean values with their standard errors)

\begin{tabular}{|c|c|c|c|c|c|c|c|c|c|c|c|c|c|c|c|c|}
\hline \multirow[b]{3}{*}{ Fatty acids } & \multicolumn{4}{|c|}{ Pretreatment ( 0 weeks) } & \multicolumn{4}{|c|}{ Supplementation for 2 weeks } & \multicolumn{4}{|c|}{ Supplementation for 4 weeks } & \multicolumn{4}{|c|}{ Washout (4 weeks) } \\
\hline & \multicolumn{2}{|c|}{ Placebo } & \multicolumn{2}{|c|}{ ARA } & \multicolumn{2}{|c|}{ Placebo } & \multicolumn{2}{|c|}{ ARA } & \multicolumn{2}{|c|}{ Placebo } & \multicolumn{2}{|c|}{ ARA } & \multicolumn{2}{|c|}{ Placebo } & \multicolumn{2}{|c|}{ ARA } \\
\hline & Mean & SE & Mean & SE & Mean & SE & Mean & SE & Mean & SE & Mean & SE & Mean & SE & Mean & SE \\
\hline $16: 0$ & $27 \cdot 8$ & 0.3 & $27 \cdot 7$ & 0.4 & 27.9 & 0.3 & 27.5 & 0.3 & 28.2 & 0.3 & $27 \cdot 3$ & 0.3 & 28.0 & 0.4 & $27 \cdot 8$ & 0.4 \\
\hline $18: 0$ & 13.7 & 0.3 & 13.7 & 0.1 & $14 \cdot 1$ & 0.2 & $14.3+\dagger$ & 0.2 & 14.0 & 0.3 & $14.3+\dagger$ & 0.2 & $13 \cdot 8$ & 0.3 & $13 \cdot 8$ & 0.2 \\
\hline $18: 1 n-9$ & 8.05 & 0.32 & 8.35 & 0.22 & 8.14 & 0.25 & 7.57 & 0.16 & $8 \cdot 16$ & 0.29 & 8.17 & 0.41 & 8.53 & 0.42 & $9 \cdot 28$ & 0.37 \\
\hline $18: 2 n-6$ & $17 \cdot 7$ & 0.9 & $19 \cdot 2$ & 0.8 & $18 \cdot 0$ & 0.9 & $16 \cdot 3+\dagger$ & 0.2 & 18.0 & 0.7 & $16 \cdot 2 \dagger+\dagger$ & 0.6 & $17 \cdot 6$ & 0.7 & 17.4 & 0.7 \\
\hline $20: 4 n-6$ (ARA) & 9.52 & 0.41 & 9.55 & 0.36 & 9.23 & 0.48 & $13 \cdot 74^{\star \star \star}+\dagger \dagger$ & 0.44 & 9.25 & 0.40 & $13 \cdot 89^{\star \star \star}+\dagger \dagger$ & 0.42 & 9.25 & 0.37 & $9 \cdot 78$ & 0.30 \\
\hline $20: 5 n-3$ (EPA) & 3.07 & 0.35 & 2.35 & 0.22 & $2 \cdot 87$ & 0.39 & 2.29 & 0.28 & $2 \cdot 67$ & 0.21 & $2 \cdot 22$ & 0.15 & 2.95 & 0.27 & $3 \cdot 12$ & 0.26 \\
\hline $22: 5 n-3$ & 1.35 & 0.07 & 1.28 & 0.05 & 1.33 & 0.06 & 1.21 & 0.04 & 1.31 & 0.06 & $1 \cdot 18$ & 0.04 & 1.35 & 0.05 & 1.33 & 0.04 \\
\hline $22: 6 n-3(\mathrm{DHA})$ & 8.63 & 0.36 & $7 \cdot 70$ & 0.33 & 8.48 & 0.35 & 7.67 & 0.32 & 8.38 & 0.37 & $7 \cdot 38$ & 0.34 & 8.84 & 0.36 & 8.08 & 0.35 \\
\hline $24: 1$ & 2.03 & 0.15 & 1.74 & 0.12 & 1.82 & 0.08 & 1.49 & 0.17 & 1.85 & 0.10 & 1.66 & 0.10 & 1.69 & 0.10 & 1.54 & 0.11 \\
\hline
\end{tabular}

Mean values were significantly different from those of the placebo (ANOVA and unpaired $t$ test): $* * * P<0.001$

Mean values were significantly different from those of the pretreatment (ANOVA and Bonferroni's correction): $+\dagger P<0.01, \mathrm{t \dagger \dagger} P<0.001$.

Table 4. Fatty acid composition ( $\mathrm{g} / 100 \mathrm{~g}$ total fatty acids) of serum TAG during the test period for the arachidonic acid (ARA) treatment group ( $n$ 12) and placebo group $(n 12)$ (Mean values with their standard errors)

\begin{tabular}{|c|c|c|c|c|c|c|c|c|c|c|c|c|c|c|c|c|}
\hline \multirow[b]{3}{*}{ Fatty acids } & \multicolumn{4}{|c|}{ Pretreatment (0 weeks) } & \multicolumn{4}{|c|}{ Supplementation for 2 weeks } & \multicolumn{4}{|c|}{ Supplementation for 4 weeks } & \multicolumn{4}{|c|}{ Washout (4 weeks) } \\
\hline & \multicolumn{2}{|c|}{ Placebo } & \multicolumn{2}{|c|}{ ARA } & \multicolumn{2}{|c|}{ Placebo } & \multicolumn{2}{|c|}{ ARA } & \multicolumn{2}{|c|}{ Placebo } & \multicolumn{2}{|c|}{ ARA } & \multicolumn{2}{|c|}{ Placebo } & \multicolumn{2}{|c|}{ ARA } \\
\hline & Mean & SE & Mean & SE & Mean & SE & Mean & SE & Mean & SE & Mean & SE & Mean & SE & Mean & SE \\
\hline $16: 0$ & $22 \cdot 1$ & 0.6 & $22 \cdot 1$ & 0.8 & $21 \cdot 9$ & 0.5 & $21 \cdot 8$ & 0.7 & $22 \cdot 4$ & 1.0 & $21 \cdot 3$ & 0.9 & $22 \cdot 7$ & 0.8 & $22 \cdot 8$ & 0.9 \\
\hline $16: 1$ & 4.51 & 0.34 & 3.98 & 0.25 & 4.39 & 0.26 & 3.92 & 0.23 & 4.59 & 0.35 & $4 \cdot 15$ & $0 \cdot 17$ & 4.89 & 0.35 & 4.86†† & 0.23 \\
\hline $18: 0$ & $2 \cdot 76$ & 0.12 & 2.91 & 0.18 & $2 \cdot 76$ & 0.12 & 3.09 & 0.17 & 2.99 & 0.20 & 3.19 & 0.27 & 2.96 & $0 \cdot 16$ & $3 \cdot 11$ & 0.17 \\
\hline $18: 1 n-9$ & 38.0 & 0.5 & 39.7 & 0.9 & 37.4 & 0.8 & 37.9 & 0.9 & 37.8 & 0.5 & 38.1 & 0.7 & 37.7 & 0.7 & $37.5 \dagger$ & 0.5 \\
\hline $18: 2 n-6$ & $20 \cdot 3$ & 0.9 & $21 \cdot 1$ & 1.0 & $21 \cdot 1$ & 1.0 & $20 \cdot 7$ & 0.6 & $20 \cdot 4$ & 1.2 & $20 \cdot 7$ & 0.6 & $19 \cdot 4$ & $1 \cdot 1$ & $19 \cdot 6$ & 0.9 \\
\hline $20: 4 n-6$ (ARA) & 1.41 & 0.10 & $1 \cdot 38$ & $0 \cdot 11$ & 1.57 & 0.23 & $2 \cdot 32 \dagger+\dagger$ & 0.28 & $1 \cdot 38$ & 0.12 & $2 \cdot 15^{\star \star} \dagger \dagger$ & $0 \cdot 17$ & 1.44 & $0 \cdot 16$ & 1.60 & 0.14 \\
\hline $20: 5 n-3$ (EPA) & $1 \cdot 24$ & 0.17 & 0.87 & $0 \cdot 10$ & $1 \cdot 21$ & 0.19 & $1 \cdot 13$ & 0.18 & 1.09 & 0.16 & $1 \cdot 11$ & 0.12 & $1 \cdot 19$ & 0.18 & $1 \cdot 28$ & 0.12 \\
\hline $22: 5 n-3$ & 1.02 & 0.06 & 0.82 & 0.05 & 1.00 & 0.07 & 0.96 & 0.08 & 0.97 & 0.06 & 0.95 & 0.06 & 0.99 & 0.07 & 1.00 & 0.07 \\
\hline $22: 6 n-3(\mathrm{DHA})$ & 4.94 & 0.52 & 3.48 & 0.36 & 5.00 & 0.52 & $4 \cdot 21$ & 0.48 & 4.87 & 0.57 & $4 \cdot 24$ & 0.47 & $5 \cdot 15$ & 0.69 & 4.63 & 0.50 \\
\hline
\end{tabular}

Mean values were significantly different from those of the placebo (ANOVA and unpaired $t$ test): ${ }^{\star *} P<0.01$

Mean values were significantly different from those of the pretreatment (ANOVA and Bonferroni's correction): $\uparrow P<0.05, \uparrow \dagger P<0.01,+\dagger \dagger P<0.001$. 
Table 5. Physical characteristics and blood biochemical parameters during the test period for the arachidonic acid (ARA) treatment group ( $n$ 12) and placebo group ( $n$ 12) $\ddagger$ (Mean values with their standard errors)

\begin{tabular}{|c|c|c|c|c|c|c|c|c|c|c|c|c|c|c|c|c|}
\hline \multirow[b]{3}{*}{ Variable } & \multicolumn{4}{|c|}{ Pretreatment (0 weeks) } & \multicolumn{4}{|c|}{ Supplementation for 2 weeks } & \multicolumn{4}{|c|}{ Supplementation for 4 weeks } & \multicolumn{4}{|c|}{ Washout (4 weeks) } \\
\hline & \multicolumn{2}{|c|}{ Placebo } & \multicolumn{2}{|c|}{ ARA } & \multicolumn{2}{|c|}{ Placebo } & \multicolumn{2}{|c|}{ ARA } & \multicolumn{2}{|c|}{ Placebo } & \multicolumn{2}{|c|}{ ARA } & \multicolumn{2}{|c|}{ Placebo } & \multicolumn{2}{|c|}{ ARA } \\
\hline & Mean & SE & Mean & SE & Mean & SE & Mean & SE & Mean & SE & Mean & SE & Mean & SE & Mean & SE \\
\hline Body weight (kg) & $67 \cdot 9$ & $2 \cdot 3$ & $70 \cdot 1$ & 1.4 & $67 \cdot 8$ & $2 \cdot 3$ & $70 \cdot 0$ & 1.3 & $68 \cdot 0$ & $2 \cdot 2$ & $70 \cdot 0$ & 1.4 & $67 \cdot 7$ & $2 \cdot 2$ & $70 \cdot 1$ & 1.4 \\
\hline BMI & $23 \cdot 2$ & 0.6 & $23 \cdot 8$ & 0.5 & $23 \cdot 2$ & 0.61 & 23.8 & 0.5 & $23 \cdot 2$ & 0.6 & $23 \cdot 7$ & 0.5 & $23 \cdot 1$ & 0.6 & 23.8 & 0.5 \\
\hline $\mathrm{SBP}(\mathrm{mmHg})$ & 120 & 3 & 125 & 3 & 122 & 3 & 122 & 4 & 119 & 3 & 122 & 4 & 121 & 3 & 124 & 4 \\
\hline $\mathrm{DBP}(\mathrm{mmHg})$ & 77 & 3 & 78 & 3 & 74 & 3 & 76 & 3 & 74 & 2 & 74 & 4 & 77 & 3 & 75 & 3 \\
\hline TAG (mg/dl) & 102 & 19 & 105 & 15 & 106 & 17 & 100 & 14 & 121 & 22 & 110 & 20 & 120 & 24 & 121 & 17 \\
\hline Total-Chol (mg/dl) & 194 & 12 & 201 & 11 & 195 & 11 & 204 & 9 & 196 & 12 & 198 & 9 & 192 & 11 & 206 & 13 \\
\hline HDL-Chol (mg/dl) & 56 & 4 & 60 & 3 & 55 & 4 & 60 & 3 & 56 & 4 & 60 & 2 & 56 & 4 & 62 & 3 \\
\hline LDL-Chol (mg/dl) & 119 & 11 & 122 & 10 & 120 & 9 & 120 & 8 & 117 & 11 & 113 & 7 & 114 & 8 & 120 & 10 \\
\hline NEFA $(\mu \mathrm{Eq} / \mathrm{l})$ & 455 & 38 & 553 & 70 & 479 & 38 & 500 & 76 & 433 & 39 & 438 & 40 & 514 & 52 & 514 & 82 \\
\hline $\mathrm{PL}(\mathrm{mg} / \mathrm{dl})$ & 199 & 11 & 208 & 13 & 206 & 14 & 221 & 12 & 207 & 12 & 207 & 10 & 202 & 10 & 219 & 11 \\
\hline AST (GOT) (U/l) & 23 & 2 & 20 & 2 & 24 & 3 & 20 & 3 & 24 & 3 & 21 & 2 & 24 & 2 & 21 & 2 \\
\hline ALT (GPT) (U/I) & 24 & 4 & 19 & 3 & 26 & 5 & 19 & 4 & 25 & 5 & 20 & 3 & 26 & 5 & 19 & 3 \\
\hline$\gamma$-GTP (U/I) & 44 & 10 & 31 & 6 & 44 & 10 & 30 & 7 & 45 & 10 & 29 & 6 & 51 & 13 & 31 & 6 \\
\hline Glucose $(\mathrm{mg} / \mathrm{dl})$ & 86 & 2 & 91 & 2 & 87 & 2 & 91 & 2 & 87 & 2 & 92 & 2 & 88 & 2 & 92 & 2 \\
\hline $\operatorname{lgE}(\mathrm{IU} / \mathrm{ml})$ & 238 & 95 & 124 & 46 & 247 & 101 & 127 & 47 & 253 & 111 & 133 & 46 & 264 & 120 & 113 & 37 \\
\hline PT (s) & $10 \cdot 4$ & 0.2 & $10 \cdot 6$ & 0.1 & $10 \cdot 4$ & 0.2 & $10 \cdot 6$ & 0.1 & $10 \cdot 3$ & 0.2 & $10 \cdot 6$ & 0.1 & $10 \cdot 3$ & 0.1 & 10.4 & $0 \cdot 1$ \\
\hline ATIII (\%) & 109 & 2 & 108 & 3 & 109 & 3 & 108 & 2 & 106 & 3 & 104 & 3 & 108 & 3 & 108 & 2 \\
\hline
\end{tabular}

ALT, alkaline phosphatase; AST, aspartate aminotransferase; ATIII, antithrombin III; Chol, cholesterol; DBP, diastolic blood pressure; $\gamma$-GTP, $\gamma$-glutamyl transpeptidase; PL, phospholipids; PT, prothrombin time; SBP, systolic blood

pressure.
$\ddagger$ No significant difference was observed between the two groups or between pretreatment and other periods for any of these parameters. 
Table 6. Platelet aggregation as percentage of maximal aggregation for the arachidonic acid (ARA) treatment group ( $n$ 12) and placebo group ( $n$ 12) $\ddagger$ (Mean values with their standard errors)

\begin{tabular}{|c|c|c|c|c|c|c|c|c|c|c|c|c|}
\hline \multirow[b]{3}{*}{ Aggregating agent } & \multicolumn{4}{|c|}{ Pretreatment (0 weeks) } & \multicolumn{4}{|c|}{ Supplementation for 4 weeks } & \multicolumn{4}{|c|}{ Washout (4 weeks) } \\
\hline & \multicolumn{2}{|c|}{ Placebo } & \multicolumn{2}{|c|}{ ARA } & \multicolumn{2}{|c|}{ Placebo } & \multicolumn{2}{|c|}{ ARA } & \multicolumn{2}{|c|}{ Placebo } & \multicolumn{2}{|c|}{ ARA } \\
\hline & Mean & SE & Mean & SE & Mean & SE & Mean & SE & Mean & SE & Mean & SE \\
\hline \multicolumn{13}{|l|}{ ADP } \\
\hline $1 \mu \mathrm{M}$ & $29 \cdot 8$ & 5.8 & $27 \cdot 3$ & 4.9 & $35 \cdot 7$ & $7 \cdot 1$ & 30.9 & 7.5 & 33.3 & $6 \cdot 9$ & $30 \cdot 7$ & $7 \cdot 0$ \\
\hline $2 \mu \mathrm{M}$ & $63 \cdot 6$ & $6 \cdot 3$ & $57 \cdot 8$ & $6 \cdot 2$ & $64 \cdot 1$ & $6 \cdot 4$ & $55 \cdot 3$ & $7 \cdot 4$ & 63.9 & 5.9 & $60 \cdot 3$ & $7 \cdot 1$ \\
\hline \multicolumn{13}{|l|}{ Collagen } \\
\hline $0.125 \mu \mathrm{g} / \mathrm{ml}$ & 22.5 & $8 \cdot 2$ & $13 \cdot 8$ & $5 \cdot 7$ & 25.5 & 8.4 & 32.5 & 9.6 & 20.5 & 8.0 & $19 \cdot 8$ & 8.0 \\
\hline $0.25 \mu \mathrm{g} / \mathrm{ml}$ & $41 \cdot 3$ & $9 \cdot 3$ & 30.9 & $7 \cdot 8$ & $54 \cdot 1 \dagger \dagger$ & 8.9 & $48.4 \dagger †$ & $9 \cdot 6$ & $51.4 \dagger$ & 8.4 & $36 \cdot 6$ & 8.3 \\
\hline \multicolumn{13}{|l|}{ ARA } \\
\hline $0.5 \mu \mathrm{M}$ & $20 \cdot 1$ & $8 \cdot 7$ & $13 \cdot 3$ & $6 \cdot 1$ & $32 \cdot 8$ & $11 \cdot 0$ & $26 \cdot 3$ & $9 \cdot 8$ & 23.4 & $9 \cdot 2$ & $19 \cdot 6$ & $8 \cdot 7$ \\
\hline $1 \mu \mathrm{M}$ & $57 \cdot 8$ & $10 \cdot 9$ & $40 \cdot 0$ & 11.0 & $60 \cdot 0$ & $10 \cdot 9$ & $46 \cdot 1$ & 11.5 & 65.4 & $10 \cdot 1$ & $40 \cdot 6$ & 11.5 \\
\hline
\end{tabular}

Mean values were significantly different from those of the pretreatment (ANOVA and Bonferroni's correction): $† P<0.05, \dagger \dagger P<0.01$.

$\ddagger$ No significant difference was observed between the two groups in any of these parameters.

Table 7. Platelet aggregation $\mathrm{ED}_{50}$ (concentration of aggregating agent required to induce half-maximal response) for the arachidonic acid (ARA) treatment group ( $n$ 12) and placebo group ( $n$ 12) $\ddagger$

(Mean values with their standard errors)

\begin{tabular}{|c|c|c|c|c|c|c|c|c|c|c|c|c|}
\hline \multirow[b]{3}{*}{ Aggregating agent } & \multicolumn{4}{|c|}{ Pretreatment (0 weeks) } & \multicolumn{4}{|c|}{ Supplementation for 4 weeks } & \multicolumn{4}{|c|}{ Washout (4 weeks) } \\
\hline & \multicolumn{2}{|c|}{ Placebo } & \multicolumn{2}{|c|}{ ARA } & \multicolumn{2}{|c|}{ Placebo } & \multicolumn{2}{|c|}{ ARA } & \multicolumn{2}{|c|}{ Placebo } & \multicolumn{2}{|c|}{ ARA } \\
\hline & Mean & SE & Mean & SE & Mean & SE & Mean & SE & Mean & SE & Mean & SE \\
\hline ADP $(\mu \mathrm{M})$ & 1.84 & 0.26 & 2.04 & 0.26 & 1.84 & 0.37 & $2 \cdot 71$ & 0.63 & 1.85 & 0.31 & $2 \cdot 67$ & 0.79 \\
\hline Collagen ( $\mu \mathrm{g} / \mathrm{ml})$ & 0.396 & 0.113 & 0.601 & 0.168 & 0.245 & 0.036 & 0.396 & $0 \cdot 104$ & 0.285 & 0.050 & 0.444 & 0.097 \\
\hline
\end{tabular}

$\ddagger$ No significant difference was observed between the two groups or between pretreatment ( 0 weeks) and other periods for these parameters.

\section{Discussion}

This double-blind, placebo-controlled study is the first to have determined the changes in fatty acid composition of serum phospholipids and TAG and in platelet aggregation induced by supplementation of ARA-enriched TAG in healthy Japanese men with a fish diet. After 2-week supplementation of $838 \mathrm{mg}$ ARA/d, ARA concentrations in serum phospholipids and TAG were significantly increased, without decrease in EPA or DHA concentrations (Tables 2 and 4) or effects on platelet aggregation (Tables 6 and 7).

All subjects of the present study kept relatively regular hours performing white-collar work and ate a set lunch or similar dishes in a cafeteria for weekday lunch. The subjects of both groups had a diet that was nearly normal in terms of energy and energy proportion (Table 2; estimated by $7 \mathrm{~d}$ weighed intake, the following similar), as did those in NILS-LSA ${ }^{62,63}$ and the INTERLIPID study ${ }^{64,65}$ for Japanese men. The fish and shellfish intake and meat intake of the subjects in the present study were nearly normal too.

Compared with Europeans ${ }^{66,67}$ and Americans ${ }^{44,68-70}$, the subjects in the present study consumed smaller amounts of total energy, fat and meat, and larger amounts of fish and shellfish and n-3 fatty acids such as EPA and DHA, but had a similar intake of ARA, in their daily diet. Although it is _generally assumed that meat provides $n-6$ fatty acids and fish and shellfish $n-3$ fatty acids, the subjects of the present study had almost the same intake of ARA as Europeans and
Americans. One possible explanation for this discrepancy in findings concerning ARA intake is that fish and shellfish are comparatively common sources of ARA, next to yolk and meat, for Japanese.

Despite the variation among subjects in intake of fatty acids, especially EPA and DHA, ARA content in serum/ plasma phospholipids at baseline in the present study was similar to pretreatment levels in healthy men in the $\mathrm{USA}^{46,69}$, patients with cirrhosis in Italy ${ }^{47}$ and healthy vegetarians in Germany ${ }^{71}$. Even at baseline in the present study, EPA and DHA contents of serum/plasma phospholipids were at the levels obtained several weeks after change to a fish $\operatorname{diet}^{68,69}$ or supplementation of fish oil ${ }^{72}, \mathrm{DHA}^{71}$ or both of them ${ }^{67,73}$ in previous studies in non-Japanese individuals.

The ARA concentration of serum phospholipids was increased by about $4 \% 2$ weeks after initiation of ARA supplementation, and this increase was still present 4 weeks later. It is possible that ARA concentration had already reached maximal level after 2 weeks of supplementation. No studies have demonstrated the existence of a maximal ARA concentration in plasma phospholipids, or that a duration of less than 2 weeks is required to reach the maximal level of ARA after initiation of supplementation of ARA using ARA-enriched TAG. In the ARA group, significant reductions (approximately $3 \%$ ) in $18: 2 n-6$ were observed after 2 and 4 weeks of treatment as well as after a 4-week washout, compared with baseline. Most of the increase in ARA concentration (which was about $4 \%$ ) can be explained by the 
decrease in $18: 2 n-6$ (approximately $3 \%$ ). The proportions of increase in ARA and reduction of $18: 2 n-6$ by ARA supplementation in the present study were consistent with the results obtained in previous ARA supplementation studies using ARA-enriched TAG in healthy subjects ${ }^{46}$ and patients with liver cirrhosis ${ }^{47}$. Notably, EPA and DHA concentrations in plasma phospholipids did not change with ARA supplementation in the present study, although decreases in ARA concentration in plasma or serum have been reported in various subjects with a fish diet or undergoing EPA and DHA supplementation $^{68,71}$. The present findings suggest the existence of multiple mechanisms for preservation of ARA, EPA and DHA in blood.

The relationship between fatty acid intake and platelet aggregation has been examined in interventional studies with healthy subjects. It has been reported that dietary fatty acid composition, i.e. of SFA, MUFA, $n-6$ and $n-3$, had a significant effect on ADP- and collagen-induced platelet aggregation $^{69}$. Several studies have found that platelet aggregation decreased with consumption of large or normal amounts of salmon $^{68}$, fish oil ${ }^{74}$ or $n-3$ fatty acid ${ }^{75}$. In a study of four subjects for whom ARA supplementation significantly decreased the threshold concentration of platelet aggregation by ADP, ethyl arachidonate was used in free and not TAG form, and an excessively large dose, $6 \mathrm{~g} / \mathrm{d}$, was used for supplementation $^{76}$. In patients with cirrhosis who had reduced platelet aggregation, addition of $2 \mathrm{~g} / \mathrm{d}$ of this agent improved platelet aggregation $^{47}$.

Addition of $1.5 \mathrm{~g}$ ARA-enriched TAG/d for $50 \mathrm{~d}$ induced no significant physiological changes in the blood coagulation and platelet aggregation systems compared with placebo treatment in the healthy American ${ }^{45}$. Although in that study they did not particularly mention intakes of EPA and $\mathrm{DHA}^{44}$, the levels of their intakes were similar to those of general European and American people. In addition, the degree of increase in plasma ARA was approximately the same as in our present study. Therefore, it may be possible to say that the fact the serum/plasma ARA elevation by supplementation does not affect platelet aggregation can be observed in not only the Japanese but also in Westerners. Of course, further study in Western countries must be performed to make the hypothesis clear.

Consumption of an appropriate variety and quantity of nutrients in the diet is important for living a healthy, long life, and habitual fish intake has been considered one of the causes of Japanese longevity. Improvement in sanitary conditions and medical advances have extended average life expectancy, especially in metropolitan areas. As a result, the number of elderly individuals unable to eat well by themselves, e.g. due to light eating or illness, is increasing. It is important to determine not only which nutrients are essential for maintaining life but also those producing a healthy, long life. The importance of supplementation of ARA and DHA, both of which are essential fatty acids, must be determined, since it has been found that most of the ARA, EPA and DHA in blood is obtained from food and that only a part of it is synthesized from linoleic acid and $\alpha$-linolenic acid in the human body ${ }^{27-31}$.

Further studies are needed to determine the effects of supplementation of ARA in nutritional products beyond infant milk in healthy subjects with or without a fish diet. Changes in fatty acid composition, not only in serum and plasma but also in erythrocyte membranes and platelets, following ARA supplementation need to be determined. The $24 \mathrm{~h}$ excretion of 2,3-dinor-6-keto prostaglandin $\mathrm{F} 1 \alpha$ and 11-dehydro-thromboxane B2, which are metabolites of ARA, should be measured. In addition, the changes that occur in fatty acid composition in serum and plasma within 2 weeks of initiation of ARA supplementation and whether platelet aggregation is altered after more than 4 weeks of supplementation should be determined.

In conclusion, no subjects discontinued participation in the study due to adverse events resulting from supplementation of ARA. No clinically significant changes in the results of physical examination or vital signs occurred in either group in the present study. It was shown that supplementation of ARAenriched TAG oil obtained from Mortierella alpina safely increased ARA concentration in serum phospholipids without decreasing EPA or DHA concentrations in healthy Japanese men with daily, moderate intake of fish in their diet.

\section{References}

1. Oliver MF (1982) Diet and coronary heart disease. Hum Nutr Clin Nutr 36, 413-427.

2. Nordoy A \& Goodnight SH (1990) Dietary lipids and thrombosis. Relationships to atherosclerosis. Arteriosclerosis 10, 149-163.

3. Shrapnel WS, Calvert GD, Nestel PJ \& Truswell AS (1992) Diet and coronary heart disease. The National Heart Foundation of Australia. Med J Aust 156, S9-S16.

4. Dyerberg J \& Bang HO (1982) A hypothesis on the development of acute myocardial infarction in Greenlanders. Scand $J$ Clin Lab Invest 161, Suppl., 7-13.

5. Hu FB \& Willett WC (2002) Optimal diets for prevention of coronary heart disease. JAMA 288, 2569-2578.

6. Wang C, Harris WS, Chung M, Lichtenstein AH, Balk EM \& Kupelnick B (2006) n-3 Fatty acids from fish or fish-oil supplements, but not $\alpha$-linolenic acid, benefit cardiovascular disease outcomes in primary- and secondary-prevention studies: a systematic review. Am J Clin Nutr 84, 5-17.

7. Kalmijn S, Launer LJ, Ott A, Witteman JC, Hofman A \& Breteler MM (1997) Dietary fat intake and the risk of incident dementia in the Rotterdam Study. Ann Neurol 42, 776-782.

8. Kalmijn S (2000) Fatty acid intake and the risk of dementia and cognitive decline: a review of clinical and epidemiological studies. J Nutr Health Aging 4, 202-207.

9. Barberger-Gateau P, Letenneur J, Deschamps V, Peres K, Dartigues JF \& Renaud S (2002) Fish, meat, and risk of dementia: cohort study. Br Med J 325, 932-933.

10. Morris MC, Evans DA, Tangney CC, Bienias JL \& Wilson RS (2005) Fish consumption and cognitive decline with age in a large community study. Arch Neurol 62, 1849-1853.

11. WHO and FAO Joint Consultation (1995) Fats and oils in human nutrition. Nutr Rev 53, 202-205.

12. Simopoulos AP, Leaf A \& Salem N (1999) Workshop on the Essentiality of and Recommended Dietary Intakes for $n-6$ and n-3 Fatty Acids. Bethesda, MD: National Institutes of Health.

13. Scientific Review Committee (1990) Nutrition Recommendations. Ottawa: Canadian Government Publishing Centre, Supply and Services Canada.

14. COMA Cardiovascular Review Group (1994) Report on Health and Social Subjects: Nutritional Aspects of Cardiovascular Disease. Report no. 46. London: Department of Health. 
15. Carlson SE (2001) Docosahexaenoic acid and arachidonic acid in infant development. Semin Neonatol 6, 437-449.

16. Larque E, Demmelmair H \& Koletzko B (2002) Perinatal supply and metabolism of long-chain polyunsaturated fatty acids: importance for the early development of the nervous system. Ann N Y Acad Sci 967, 299-310.

17. Crawford MA, Golfetto I, Ghebremeskel K, Min Y, Moodley T, Poston L, Phylactos A, Cunnane S \& Schmidt W (2003) The potential role for arachidonic and docosahexaenoic acids in protection against some central nervous system injuries in preterm infants. Lipids 38, 303-315.

18. Groot RH, Hornstra G, van Houwelingen AC \& Roumen F (2004) Effect of alpha-linoleic acid supplementation during pregnancy on maternal and neonatal polyunsaturated fatty acid status and pregnancy outcome. Am J Clin Nutr 79, 251-260.

19. Innis SM, Adamkin DH, Hall RT, et al. (2002) Docosahexaenoic acid and arachidonic acid enhance growth with no adverse effects in preterm infants fed formula. J Pediatr 140, 547-554.

20. Clandinin MT, Van Aerde JE, Merkel KL, Harris CL, Springer MA, Hansen JW \& Diersen-Schade DA (2005) Growth and development of preterm infants fed infant formulas containing docosahexaenoic acid and arachidonic acid. J Pediatr 146, 461-468.

21. Agostoni C, Trojan S, Bellu R, Riva E \& Giovannini M (1995) Neurodevelopmental quotient of healthy term infants at 4 months and feeding practice: the role of long-chain polyunsaturated fatty acids. Pediatr Res 38, 262-266.

22. Birch EE, Garfield S, Hoffman DR, Uauy R \& Birch DG (2000) A randomized controlled trial of early dietary supply of longchain polyunsaturated fatty acids and mental development in term infants. Dev Med Child Neurol 42, 174-181.

23. Bouwstra H, Dijck-Brouwer DAJ, Wildeman JAL, Tjoonk HM, Van der Heid JC, Boersma ER, Muskiet FAJ \& HaddersAlgra M. (2003) Long-chain polyunsaturated fatty acids have a positive effect on the quality of general movements of healthy term infants. Am J Clin Nutr 78, 313-318.

24. ESPGAN (European Society of Pediatric Gastroenterology and Nutrition) Committee on Nutrition (1991) Comment on the content and composition of lipids in infant formulas. Acta Paediatr Scand 80, 887-896.

25. The British Nutrition Foundation (1992) Recommendations for intakes of unsaturated fatty acids. In Unsaturated Fatty Acids: Nutritional and Physiological Significance, pp. 153-163. London: Chapman and Hall, 179.

26. Report of the SCF (Scientific Committee on Food) on the essential requirements for infont formulae and follow-on formulae. Opinion expressed on 17 September 1993.

27. Brenner RR (1977) Regulatory function of delta6 desaturate key enzyme of polyunsaturated fatty acid synthesis. Adv Exp Med Biol 83, 85-101.

28. Burdge GC, Jones AE \& Wootton SA (2002) Eicosapentaenoic and docosapentaenoic acids are the principal products of alphalinolenic acid metabolism in young men. Br $J$ Nutr 88, $355-363$.

29. Pawlosky R, Hibbeln J, Lin Y, Salem N Jr \& Burdge G (2003) Nutrition Discussion Forum. Br J Nutr 90, 993-995.

30. De Gomez-Dumm I \& Brenner RR (1974) Oxidative desaturation of alpha-linolenic, linoleic and stearic acids in human liver microsomes. Lipids 10, 315-317.

31. McCloy U, Ryan MA, Pencharz PB, Ross RJ \& Cunnane C (2004) A comparison of the metabolism of eighteen-carbon ${ }^{13} \mathrm{C}$-unsaturated fatty acids in healthy women. J Lipid Res $\mathbf{4 5}$, $474-485$.

32. Miyamoto E (2006) Molecular mechanism of neuronal plasticity: induction and maintenance of long-term potentiation in the hippocampus. J Pharmacol Sci 100, 433-442.
33. Lynch MA \& Voss KL (1994) Membrane AA concentration correlates with age and induction of long-term potentiation in the dentate gyrus in the rat. Eur J Neurosci 6, 1008-1014.

34. Murray CA \& Lynch MA (1998) Evidence that increased hippocampal expression of the cytokine interleukin- $1 \beta$ is a common trigger for age- and stress-induced impairments in long-term potentiation. J Neurosci 18, 2974-2981.

35. Lynch MA, Voss KL \& Gower AJ (1994) Impaired spatial memory in aged rats is associated with alterations in inositol phospholipid metabolism. Neuroreport 5, 1493-1497.

36. McGahon B, Clements MP \& Lynch MA (1997) The ability of aged rats to sustain long-term potentiation is restored when the age-related decrease in membrane AA concentration is reversed. Neuroscience 81, 9-16.

37. McGahon BM, Murray CA, Horrobin DF \& Lynch MA (1999) Age-related changes in oxidative mechanisms and LTP are reversed by dietary manipulation. Neurobiol Aging 20, $643-653$.

38. Kotani S, Nakazawa H, Tokimasa T, Akimoto K, Kawashima H, Toyoda-Ono Y, Kiso Y, Okaichi H \& Sakakibara M (2003) Synaptic plasticity preserved with AA diet in aged rats. Neurosci Res 46, 453-461.

39. Sakuradani E, Kobayashi M \& Shimizu S (1999) $\Delta 9$-Fatty acid desaturase from arachidonic acid-producing fungus: unique gene sequence and its heterologous expression in a fungus. Eur J Biochem 260, 208-216.

40. Streekstra H (1997) Review: On the safety of Mortierella alpine for the production of food ingredients, such as arachidonic acid. J Biotechnol 56, 153-165.

41. Hempenius RA, van Delft JMH, Prinsen M \& Lina BAR (1997) Preliminary safety assessment of an arachidonic acid-enriched oil derived from Mortierella alpine: summary of toxicological data. Food Chem Toxicol 35, 573-581.

42. Hempenius RA, Lina BAR \& Haggit RC (2000) Evaluation of a sub-chronic (13-week) oral toxicity study, preceded by an in utero exposure phase, with arachidonic acid oil derived from Mortierella alpine in rats. Food Chem Toxicol 38, 127-139.

43. Lina BAR, Wolterbeek APM, Suwa Y, Fujikawa S, Ishikura Y, Tuda S \& Dohnalek M (2006) Subchronic (13-week) oral toxicity study, preceded by an in utero exposure phase, with arachidonate-enriched triglyceride oil (SUNTGA 40S) in rats. Food Chem Toxicol 44, 326-335.

44. Nelson GJ, Kelley DS, Emken EA, Phinney SD, Kyle D \& Ferretti A (1997) A human dietary arachidonic acid supplementation study conducted in a metabolic research unit: rationale and design. Lipids 32, 415-420.

45. Nelson GJ, Schmidt PC, Bartolini G, Kelley DS \& Kyle D (1997) The effect of dietary arachidonic acid on platelet function, platelet fatty acid composition, and blood coagulation in humans. Lipids 32, 421-425.

46. Nelson GJ, Schmidt PC, Bartolini G, Kelley DS, Phinney SD, Kyle D, Silbermann S \& Schaefer EJ (1997) The effect of dietary arachidonic acid on plasma lipoprotein distributions, apoproteins, blood lipid levels, and tissue fatty acid composition in humans. Lipids 32, 427-433.

47. Pantaleo P, Marra F, Vizzutti F, Spadoni S, Ciabattoni G, Galli C, Villa GL, Gentilini P \& Laffi G (2004) Effects of dietary supplementation with arachidonic acid on platelet and renal function in patients with cirrhosis. Clin Sci 106, 27-34.

48. Nakamura T, Takebe K, Tando Y, Arai Y, Yamada N, Ishii M, Kikuchi H, Machida K, Imamura K \& Terada A (1995) Serum fatty acid composition in normal Japanese and its relationship with dietary fish and vegetable oil contents and blood lipid levels. Ann Nutr Metab 39, 261-270.

49. Sugano M \& Hirahara F (2000) Polyunsaturated fatty acids in the food chain in Japan. Am J Clin Nutr 71, 189S-196S. 
50. Kobayashi M, Sasaki S, Kawabata T, Hasegawa K, Akabane M \& Tsugane S (2001) Single measurement of serum phospholipid fatty acid as a biomarker of specific fatty acid intake in middleaged Japanese men. Eur J Clin Nutr 55, 643-650.

51. Kobayashi M, Sasaki S, Kawabata T, Hasegawa K, Tsugane S \& JPHC (2003) Validity of a self-administered food frequency questionnaire used in the 5-year follow-up survey of the JPHC Study Cohort I to assess fatty acid intake: comparison with dietary records and serum phospholipid level. J Epidemiol 13, Suppl. 1, S64-S81.

52. Kuriki K, Nagaya T \& Tokudome Y (2003) Plasma concentrations of (n-3) highly unsaturated fatty acids are good biomarkers of relative dietary fatty acid intakes: a cross-sectional study. J Nutr 133, 3643-3650.

53. Ministry of Education, Culture, Sports, Science and Technology (2005) Fatty acids section. In Standard Tables of Food Composition in Japan, 5th ed. Tokyo: Ministry of Education, Culture, Sports, Science and Technology.

54. Folch J, Lees M \& Stanley GHS (1957) A Simple method for the isolation and purification of total lipids from animal tissues. J Biol Chem 226, 497-509.

55. Ikuta S, Imamura S, Misaki H \& Horiuti Y (1977) Purification and characterization of choline oxidase from Arthrobacter globiformis. J Biochem 82, 1741-1749.

56. Warnick GR, Nauck M \& Rifai N (2001) Evolution of methods for measurement of HDL-cholesterol: from ultracentrifugation to homogeneous assays. Clin Chem 47, 1579-1596.

57. Nauck M, Warnick GR \& Rifai N (2002) Methods for measurement of LDL-cholesterol: a critical assessment of direct measurement by homogeneous assays versus calculation. Clin Chem 48, 236-254.

58. Sakurabayashi I (1986) Latex-agglutination immunoassay. Rinsho Byori 34, 887-892.

59. Kanno T (1987) Automation of the immunochemical laboratory using the latex agglutination reaction. Rinsho Byori 35, 874-877.

60. Born GVR (1962) Aggregation of blood platelets by adenosine diphosphate and its reversal. Nature 194, 927-929.

61. Packham MA (1984) Standardization of collagen: consideration of current practices in testing collagen-induced aggregation. Thromb Haemost 52, 358-361.

62. Shimokata H, Ando F \& Niino N (2000) A new comprehensive study on aging - the National Institute for Longevity Sciences, Longitudinal Study of Aging (NILS-LSA). J Epidemiol 10, $\mathrm{S} 1-\mathrm{S} 9$.

63. Imai $\mathrm{T}$, Sakai $\mathrm{S}$, Mori $\mathrm{K}$, Ando $\mathrm{F}$, Niino $\mathrm{N}$ \& Shimokata $\mathrm{H}$ (2000) Nutritional assessments of 3-d dietary records in National Institute for Longevity Sciences - Longitudinal Study of Aging (NILS-LSA). J Epidemiol 10, S70-S76.

64. Ueshima H, Okayama A, Saitoh S, Nakagawa H, Rodriguez B, Sakata K, Okuda N, Choudhury SR \& Curb JDfor the INTERLIPID Research Group (2003) Differences in cardiovascular disease risk factors between Japanese in Japan and JapaneseAmericans in Hawaii: the INTERLIPID study. J Hum Hypertens 17, 631-639.
65. Okuda N, Ueshima H, Okayama A, Saitoh S, Nakagawa H, Rodriguez B, Sakata K, Choudhury SR \& Curb JDfor the INTERLIPID Research Group (2005) Relation of long chain n-3 polyunsaturated fatty acid intake to serum high density lipoprotein cholesterol among Japanese men in Japan and Japanese-American men in Hawaii: the INTERLIPID study. Atherosclerosis 178, 371-379.

66. Sanders TAB (2000) Polyunsaturated fatty acids in the food chain in Europe. Am J Clin Nutr 71, 176S-178S.

67. Thies F, Nebe-von-Caron G, Powell JR, Yaqoob P, Newsholme EA \& Calder PC (2001) Dietary supplementation with eicosapentaenoic acid, but not with other long-chain n-3 or n-6 polyunsaturated fatty acids, decreases natural killer cell activity in healthy subjects aged $>55 \mathrm{y}$. Am J Clin Nutr 73, 539-548.

68. Nelson GJ, Schmidt PC \& Corash L (1991) The effect of a salmon diet on blood clotting, platelet aggregation and fatty acids in normal adult men. Lipids 26, 87-96.

69. Lahoz C, Alonso R, Ordovas JM, Lopez-Farre A, de Oya M \& Mata P (1997) Effects of dietary fat saturation on eicosanoid production, platelet aggregation and blood pressure. Eur $J$ Clin Invest 27, 780-787.

70. Kris-Etherton PM, Taylor DS, Yu-Poth S, Huth P, Moriarty K, Fishell V, Hargrove RL, Zhao G \& Etherton TD (2000) Polyunsaturated fatty acids in the food chain in the United States. Am J Clin Nutr 71, 179S-188S.

71. Geppert J, Kraft V, Demmelmair H \& Koletzko B (2005) Docosahexaenoic acid supplementation in vegetarians effectively increase omega-3 index: a randomized trial. Lipids 40, 807-814.

72. Harris WS, Sands SA, Windsor SL, Ali HA, Stevens TL, Magalski A, Porter CB \& Borkon AM (2004) Omega-3 fatty acids in cardiac biopsies from heart transplantation patients. Correlation with erythrocytes and response to supplementation. Circulation 110, 1645-1649.

73. Vidgren HM, Agren JJ, Schwab U, Rissanen T, Hanninen O \& Uusitupa MI (1997) Incorporation of n-3 fatty acids into plasma lipid fractions, and erythrocyte membranes and platelets during dietary supplementation with fish, fish oil, and docosahexaenoic acid-rich oil among healthy young men. Lipids 32, $697-705$.

74. Rogers S, James KS, Butland BK, Etherington MD, O'Brien JR \& Jones JG (1987) Effects of a fish oil supplement on serum lipids, blood pressure, bleeding time, haemostatic and rheological variables. A double blind randomised controlled trial in healthy volunteers. Atherosclerosis 63, 137-143.

75. Kristensen SD, Schmidt EB \& Dyerberg J (1989) Dietary supplementation with n-3 polyunsaturated fatty acids and human platelet function: a review with particular emphasis on implications for cardiovascular disease. J Intern Med 731, Suppl., $141-150$.

76. Seyberth HW, Oelz O, Kennedy T, Sweetman BJ, Danon A, Frolich JC, Heimberg M \& Oates JA (1975) Increased arachidonate in lipids after administration to man: effects of prostaglandin biosynthesis. Clin Pharmacol Therapeut 18, 521-529. 